\title{
EFFECTIVE FACTORS ON ADOPTION OFINNOVATION IN ORGANIZATIONAL IT ACCORDING TO ORGANIZATIONAL, ENVIRONMENTAL, INNOVATION AND HUMAN FACTORS IN ZANJAN INDUSTRIAL TOWNS
}

\author{
S. Alamati ${ }^{1, *}$, S. M. B. Jafari ${ }^{2}$ \\ ${ }^{1}$ Master of Governmental Management, Farabi Campus, University of Tehran, Gom, Iran \\ ${ }^{2}$ Assistant professor, Department of Management, Farabi Campus, University of Tehran, Gom, \\ Iran
}

Published online: 16 July 2016

\begin{abstract}
This research studies adoption of innovation in information technology. New technologies have numerous advantages for companies and can be considered as competitive advantage that cause to efficacy and development in these companies. The research aims is to investigate the effective factors in adoption of innovation in IT in the mentioned industries. This research was conducted examining innovation factors, organizational factors, environmental factors and human factors in organizational level. For measuring the effectiveness of each dimension and determining the coefficient of each effective variable, SPSS was used. The data were collected from the companies working based on IT. The results showed that innovation factors, organizational factors and human factors have a positive and significant effect on adoption of new technologies. The results of analysis of regression
\end{abstract}

Author Correspondence, e-mail: alamatisomayeh@yahoo.com doi: http://dx.doi.org/10.4314/jfas.8vi2s.69

Journal of Fundamental and Applied Sciences is licensed under a Creative Commons Attribution-NonCommercial 4.0 International License. Libraries Resource Directory. We are listed under Research Associations category. 
and simple linear regression revealed that organizational and innovation variables have highest coefficients with most effectiveness in adoption of new technologies in IT.

Keywords: innovation; information technology;adoption of new technologies in IT; industrial towns

\section{INTRODUCTION}

Innovation in information technology has a significant effect on organizations and adoption of innovation in organizations increases quality and productivity and also, organizational interactions and participations. Comparison of changes in recent three decades shows that they have a significant difference with past which the main reason is related to revolutions happened in these decades. Revolutions in information and communication domain paved the way to era of information and communication. The main factor leading to such condition is "Information technology" (IT). Undoubtedly, all countries are aware of the importance of progress of IT as a device for development in all scopes and in some cases, it is considered as middle way for developing countries. Nowadays, IT is the main provider of the facilities for companies[1,2] and also, IT has capabilities that facilitates fundamental changes in the structure and management of organizations and also, innovation in IT has a significant effect on organizations and its adoption promotes quality and also organizational interactions and participation. In recent years, the advantages ofadoption of innovation in IT have led the IT scholars to examine this issue broadly.Adoption of innovation in IT has been studied from different perspectives including Rogers's adoption of innovation theory and resource dependency theory. These viewpoints have expanded complementary according to adoption of innovation in IT[3].

New technologies have been converted to one of the key factors of success that are essential in most of the state and private organizations [4].However, these organizations orientation regarding realization of their mission by adoption ofinnovation should be analyzed from management and its infrastructural sub-systems point of view. Today, many factors have caused the governmental organizations to ignore the issue of innovation and as a result, they left the sphere of competition. Of the important factors can be referred as follows:

1- The owners' subjectivity;

2- Organizational dimensions;

3- Weakness of the users in employing new technologies; 
4- Resistance against change;

5- Limitation of employing new technologies in some scopes[5].

If the managers do not understand need for modernization in their organizations, they could not benefitnot only from their resources potential advantages, but also from their human resources capacities. Due to the ability of the industrial towns to coping with environmental changing conditions and also these companies' role in industrial sustainable development, adoption of new technologies in these companies should be focused. Hence, this adoption seems essential in Zanjan Province Industrial Towns and it is one of the main goals of this research.

\section{Research background}

\subsection{Theoretical foundations}

Adoption of innovation process introduces a new product or an action [2]. Adoption is a decision making made for innovation [7] and adoption of innovation is production, development and using new measures [8]. Adoption of IT is described as using software and hardware for supporting commercial operations, organizational management and decision making processes[9].

It can be done via reaction to changes in the environmental conditions or when adoption of innovation is considered essential for organizational common practices, it can be promoted by management decisions believing that it increases organizational performance [10]. Studies on adoption of innovation can be classified into two categories of innovation processes and innovation contradictions. King investigated the innovation processes, diffusion of innovation and organizational innovation. Rogers studied innovation contradiction and its effect on organizational determinatives of adoption of innovation and the effect of adoption of innovation on organizational performance [10].

In this regard, the researchers propose two main approaches for investigating innovation research [11]:

\section{a) Process view \\ b) Structural view}

Process view tests organizational behavior which has been experienced in the adoption period that employs innovation and structural view tests innovation by this assumption that it influences the adoption of innovation and diffusion of innovation patterns [12]. 
Research on diffusion of innovation and adoption of IT has proposed theories and frameworks related to adoption and diffusion of information technology in the organization. The models of adoption of innovation test personal decisions for adoption or rejection of a specific innovation while the diffusion of innovation models describe how an innovation is accepted in a society. Premkumar believes that the research on diffusion of innovation of IT requires continuous investigation of the models of adoption of innovation of IT according to the reasons for events in adoption process. Chin and Markulin suggested various practical measures for test of views and broad application of information technology. Hence, a research model for adoption of IT should visualize the concepts that increase our perception on various steps of adoption and using processes.

\subsection{Empirical foundation}

a) National studies: No significant studies have been carried out in this regard in the national level; however, Verdinejad and Amiri [13] investigated the impact of new technologies on competitive advantages of Islamic Republic News Agency (IRNA) in 2009. New technologies are divided into five dimensions dependent on technique, knowledge, reaction, process and intermediacy that can be effective in competitive advantages. In current conditions, the competitive advantages depend on technology as a system dependent technique and tool, while the results of research depict that IRNA optimal competitive advantage relies on technology as knowledge and technology as process. The results showed that IRNA competitive advantage requires empowering in all five dimensions. However, IRNA can increase itspower in the competition scope via changing its organizational structure proportionate with new communicative technologies. Sanobar and Salmani [14] investigated the effectiveness of innovation stimuli in innovation capacity of knowledge- based companies in 2011. Regarding to the importance and necessity of increasing the capacity of innovation in organization, there are significant experiential and theoretical evidences supporting that the main research focuses on the identification of the effectiveness of each innovation stimulus (knowledge management, innovation and creativity management, and IT management in businesses) on innovation capacity in knowledge based companies in the Science and Technology Center. The results of the research showed that each stimulus has a significant and positive effect on creation and increase of innovation capacity. Among these variables, IT management and knowledge 
management have highest coefficients which means highest effectiveness on creation of innovation, increase of capacity and main stimuli in businesses.

b) International studies: numerous studies have been done on adoption of new technologies in international level and approximately similar results have been achieved.

Damanpour and Schnaider [15] studied the steps of adoption of innovation in organizations and the effect of three factors of top managers, organization and environment in this regards in 1991. They found that each dimension depicts the same difference in adoption of innovation, organizational features and characteristics of top managers and attitude to innovation has a strong effect relative to organizational features and characteristics of top managers. Simon and Naji [16] investigated adoption of IT qualitatively in 2007 and identified three main factors that influence significantly adoption of WBT in Hong Kong including:

1. Cost;

2. Organizational readiness;

3. External pressures.

Jos Moyano and Sebastian Bracue [17] studied organizational factors in adoption and using of IT in small and medium firms in 2007. The aim of their research was to identify the level and speed of effective factors in adoption of information. The results showed that some intrinsic factors includesuccess in decision to adoption on one hand and application process on the other hand.

Therefore, other systems have been used for socialization of the staff and their shifting in order to having sample, concurrent utilization of information and quality systems and expertise. Existence of significant difference in the results is due to decision toadoption of web technology in different times in the studied firms. This research has discussed the findings.

\section{Research model}

After reviewing related literature and finding effective factors on adoption of innovation in IT and examining the research results [18] and according to the research hypotheses, the theoretical model mentioned in figure 1 was proposed. Based on the theoretical and experiential studies and the research model, the aim of the research is to test following hypotheses:

a. Main hypotheses: innovation factors, organizational factors, environmental factors and human factors influence adoption of innovation in technologies.

b. Secondary hypotheses:

1. Innovation factors are effective in adoption of innovation in IT? 
2. Organizational factors are effective in adoption of innovation in IT?

3. Environmental factors are effective in adoption of innovation in IT?

4. Human factors are effective in adoption of innovation in IT?

\section{RESEARCH METHODOLOGY}

This research is applied according to goal and descriptive and survey in terms of methodology. In this research, in order to examine the effective factors on adoption ofinnovation in IT, the data obtained by questionnaires distributed in firms working based on IT were used. The sampling was done by cluster random sampling method and the sample size was determined 199 by Morgan formula. 270 questionnaires were distributed and 199 questionnaires were returned. The questionnaire included 53 items chosen according to the previous studies in two sections. The first section included questions on the respondent demographic variables and the second section measured four variables. For measuring variables of innovation factors, organizational factors, environmental factors, human factors and adoption of innovation in IT, Likert's Scale was used from 5 (completely agree)to 1(completely disagree).

For measuring the validity, the questionnaires were distributed among 40 members of the research population and the data were analyzed and some of the questions were reviewed and some of them were removed and then completed by ten experts. For measuring the reliability of the questionnaire, Cronbach's alpha was calculated. The results showed that the Cronbach's alpha coefficient is acceptable in all sections. Table 1 shows the Cronbach's alpha coefficients for each variable. 


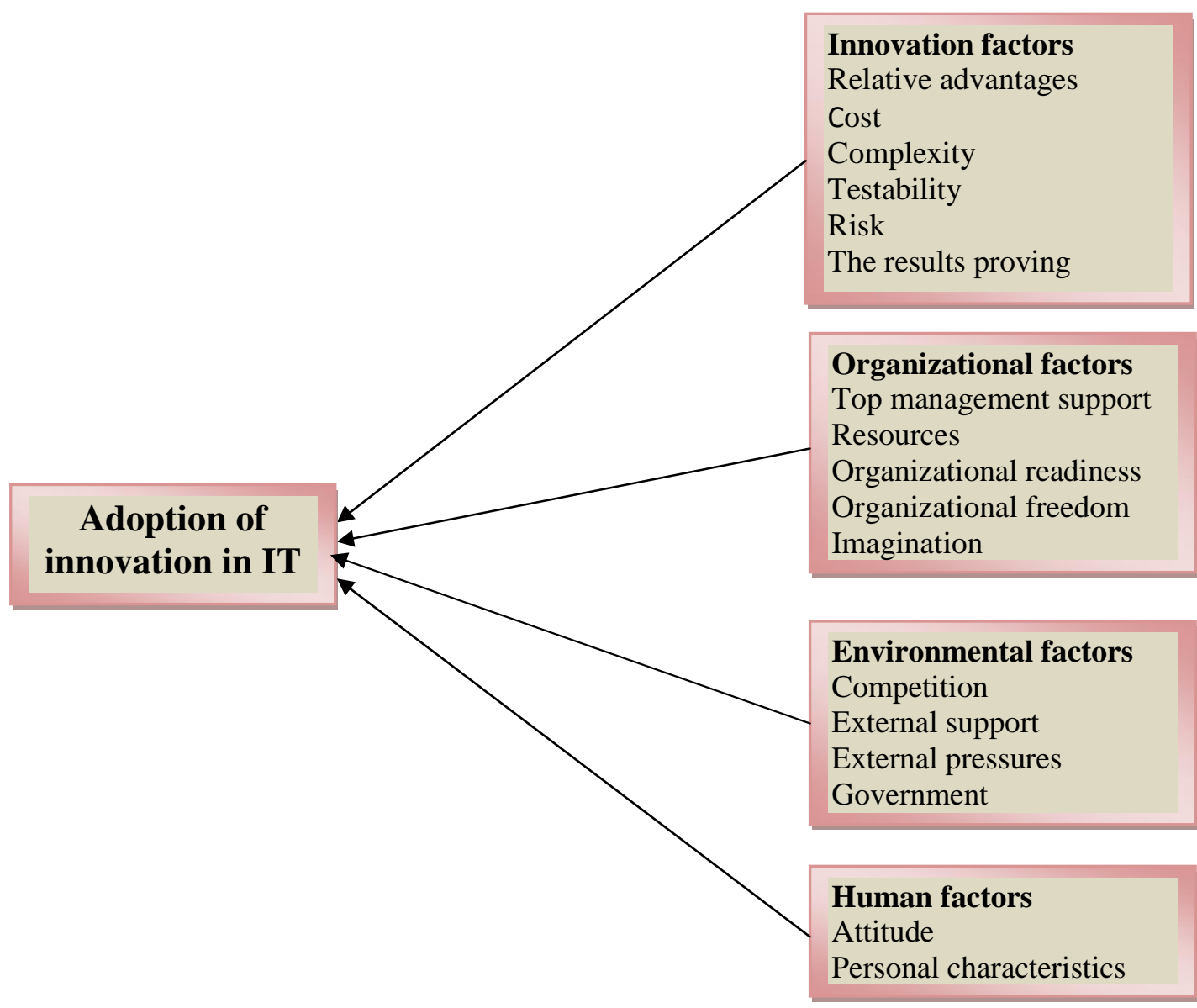

Fig.1. The research model has been adopted from Abdulhamid Momtaz, Stokancel, Stephen Swift (2012)

Table 1: Cronbach's alpha

\begin{tabular}{|c|c|c|}
\hline Variable & Questions & Cronbach's alpha \\
\hline Innovation factors & 16 & 0.81 \\
\hline Organizational factors & 16 & 0.83 \\
\hline Environmental factors & 11 & 0.88 \\
\hline Human factors & 5 & 0.84 \\
\hline Adoption of innovation in IT & 5 & 0.89 \\
\hline
\end{tabular}

\section{Findings of research}

At firstdescriptive statistics were used to analyze the data of the first part of the questionnaire related to demographic variables and the data of the second part of the questionnaire were analyzed using software SPSS. In this study, the highest and lowest percentage of respondents in 
terms of education variable was $51.2 \%$ with undergraduate and $7 \%$ with $\mathrm{PhD}$ degree. In terms of gender variable, majority of the respondents with $54.8 \%$ were men and the rest were women. The status of the respondents in terms of organizational place was investigated that $52.3 \%$ and $47.7 \%$ were IT managers and experts and their working experience showed that the individuals less than 5 years of work experience constitute $54.8 \%$ of the respondents.

\subsection{Research tests}

In this study, the average test of a sample was used to measure the different dimensions and research components compared to the average, then using Friedman, the main dimensions of the research under the current state were rated, the using stepwise regression the effects of independent variables (innovation, organizational, environmental and human factors) on the dependent variable (the adoption of innovation in information technology) were discussed. The resultsobtained by stepwise linear regression are shown in Table 2.

Table 2: Regression test result between independent variables and the dependence variable

\begin{tabular}{|c|c|c|c|c|c|c|}
\hline Characteris & $\begin{array}{l}\text { of Entered va } \\
\text { gression mode }\end{array}$ & les in & & $\begin{array}{r}\operatorname{Re} \\
\text { cl }\end{array}$ & $\begin{array}{l}\text { ressior } \\
\text { aracte }\end{array}$ & $\begin{array}{l}\text { odel } \\
\text { cs }\end{array}$ \\
\hline $\begin{array}{l}\text { Entered } \\
\text { variable }\end{array}$ & $\begin{array}{c}\text { Coefficient in } \\
\text { model (B) }\end{array}$ & $\beta$ & Sig. & $\mathrm{F}$ & Sig. & $\mathbf{R}^{2}$ \\
\hline Fixed value & -1.340 & - & 0.002 & \multirow{4}{*}{43.0926} & \multirow{4}{*}{0.000} & \multirow{4}{*}{0.403} \\
\hline $\begin{array}{l}\text { Organizational } \\
\text { factors }\end{array}$ & 0.473 & 0.457 & 0.000 & & & \\
\hline $\begin{array}{l}\text { Innovation } \\
\text { factors }\end{array}$ & 0.799 & 0.427 & 0.000 & & & \\
\hline Human factors & 0.122 & 0.125 & 0.041 & & & \\
\hline
\end{tabular}

The above table shows that the first entered variable is organizational factors, the second variable is innovation factors andthe third variable is human factors, but environmental factors variable had no requirement for entry into the model. Coefficients of innovation, organizational and human factors in the modelare determined byequivalent coefficients $(\beta)$, about $46 \%$ of the variability in the dependent variable is determined by human factors and in regression, 0.473 and 0. 799 show the highest impact of innovation factors relative to organizational factors and human 
factors. The variability in the dependent variable is explained by organizational factors; approximately $43 \%$ of total $40.3 \%$ of total variance obtained by the regression model.

\subsection{Results of hypothesis tests}

According to the tests, the linear regression model and stepwise regression model have sufficientsignificance andexplain total $40.6 \%$ of the population variance. In each variable in a simple regression, innovation factors, organizational factors and human factors are of importance and in the stepwise regression, the first variable is organizational factors and then innovation factors.In both tests, environmental factors had no requirements for entering the model and according to the interpretation of the results this variable can be assumed theoretically and by proving this hypothesis, the research by Premkumar and Margaret and Roberts is confirmed that adoption of innovation is related to innovation, organizational, environmental and human factors and the relative advantages, reduce costs, lack of sophistication, testability, lack of risk, the ability to prove results, top management support, resource allocation requirements, organizational readiness, organizational freedom, organization vision, attitude and personal traits, each as a secondary effective factors depict that by improving these components, adoption of innovation in IT is also increased.But environmental factors including state, external pressures, external support and competitive were ineffective in adoption of innovation in IT. In studies conducted by Premkumar, Margaret Roberts the environmental factorscomponents such as external pressure, external support, and competitive pressure were not significant.

In this study, the researcher proposed a model adopted from AbdulhamidMomtaz, Stokansel and Stephan Swift model. This model that has been constructed by integration of theoretical perspectives on adoption of innovation in IT and users' adoption model include 4 components of innovation, organizational, environmental and human factors. This model evaluates process of adoption of information technology in adoption-decision making stepin the organizational analysis level. This research was effective in increasing understanding of the process of adoption of information technology in the studied companies and also research knowledge from previous studies using a conceptual model. In addition, managers can consider these factorsand also evaluate the conditions for adoption of innovation in IT and also factors leading to successful adoption of technology in the organization and also prepare the proper conditions for adoption of new technologies. 


\section{CONCLUSIONS AND RECOMMENDATIONS}

The findings may have implications for IT experts, technology providers and the institutions that are responsible for promoting the adoption of new technologies and their application. So the experts and suppliers of IT are recommended to have positive attitudes towards the adoption of new technologies and also in search of indicators of behavior in order to accept new innovative technologies.New technologies provide the basis for the adoption and use of innovation.

The managers who are reluctant to adoption and use new technologies should be responsible for the experts of IT and its providers and take action to inform them and provide contexts for adoption by instructing on its advantages and importance. Adoption and implementation of innovation may create favorable attitudes in managers. This study shows that innovation factors and organizational factors have a significant impact on the adoption of innovation in IT.

The most important issue of the adoption and use of new information technologies in the industrial sector is the problem of integration, namely the exchange of information among designers, consultants, builders, clients and contractors. The fact is that most of the current information technologies have been designed without considering total process and the place of a specific program in the process and its compatibility with other software. Considering these problems and according to this fact that each project may have a broad extent and purposes, information technology in the near future probably will have supportive role and not strategic role.Information technology will be used to achieve production on a small scale - not for strategic advantage over competitors - and doing low level activities - not at the level of senior management. Leaving behind the era of data processing and the use of basic and strategic excellence in information technology, need to overcome the current situations. Achieve strategic advantage with information technology requires a revision of the traditional rules of the decisionmaking process. In industry, every sector has its own professional domain and the border of these areas is rarely broken. The companies or contractors who implement projects as EPC can use IT.

Although this study investigates the factors such as innovation, organizational factors, environmental and human factors and indicators related to the adoption of innovation in information technology, there are other factors affect the adoption of innovation in IT. Other studies can investigate these factors. In addition, studying this issue can be beneficial in different geographical areas and can provide useful information on adoption and application of new 
technologies. Therefore, these studies aid the experts of IT to have more chance to increase adoption of new technologies. In this regard, other research should consider development of culture of adoption of innovation in information technology.

\section{REFERENCES}

1. Hubber, P.J., Chau, P.Y.K., Sheng, O.R.L., Adoption of telemedicine technology by health care organizations: an exploratory study. Journal of Organizational Computing and Electronic Commerce 12 (3), 197-221,2002.

2. Darmawan, I.,. Adoption and Implementation of information technology in Bali's local government,InternationalEducation Journal 2 (4), 100-124,2001.

3. Thong, J.Y.L., Resource constraints and information systems implementation in Singaporean small businesses, Omega, International Journal of Management Science 29 (2), $143-156,2001$.

4. Momtaz,A,Councell,S.,Swift,S.,A Conceptual model For The Process Of IT Innovation Adoption In

Organization, 367,2012.

5. Et al, first edition, Tehran, Payam Noor University Press, 2007

6. Nasiri, Zangabad, "The adoption of new technologies”, 307-312, Consultants Articles, 2007.

7. Damanpour, F., Wischnevsky, J.D.,Research on organizational innovation: distinguishing innovation-generating from innovation-adopting organizations,Journal of Engineering and Technology Management 23 (4), 269-291,2006.

8. Evanisko, M, Kimberly, R., Organizational innovation, The academy of management journal, 24(4) 689-713,1971.

9. Damanpour, F, Organizational innovation: a meta-analysis of effects of determinants and moderators Academy of Management Journal 34 (3), 555-590, 1991.

10. Thong, J.Y.L., Yap, C.S., Raman, K.S., Top management support in small business information systems: how important is it? Information Systems Research 7 (2), 248-267, 1996.

11. Subramanian, A., Nilakanta, S., Organizational innovativeness: exploring the relationship between organizational determinants of innovation, types of innovations, and measures of organizational performance. Omega, International Journal Management Science 24 (6), 631$647,1996$. 
12. Benbasat, I., An analysis of research methodologies. In: McFarlan, W.F. (Ed.), The Information Systems Research Challenges, Harvard Business School Press, 47-85, 1984.

13. Wolfe, R.A., Organizational innovation: review, critique, and suggested research directions, Journal of Management Studies, 31 (3), 405-431,1994.

14. Verdi Nejad, Feridun; Amiri, Mojtaba; Bahrami, Shahla; “ The impact of new technologies on the Islamic Republic News Agency advantage”, first year, third number, 175-192, 2009. 15. Sanobar, Naser; Salmani, Behzad; Tajvidi, Mina; "The impact of innovation stimuli on innovation capacity of knowledge-based companies", Academic and Research Journal, Issue II, 2011.

16. Damanpour, F., Schneider, M., Characteristics of innovation and innovation adoption in public organizations: assessing the role of managers. Journal of Public Administration Research \& Theory 19 (3), 495-522, 2009.

17. Nagi .E, Simon.Ch; Logistics information systems: the Hong Kong experience, International Journal of Production Economics, 113(1):223-34,2008.

18. Moyano.J, Bruque.S., Organisational determinants of information technology adoption and implementation in SMEs: The case of family and cooperative firms, Technovation, 27, 241253, 2007.

How to cite this article:

Alamati S, Jafari S M B. Effective factors on adoption ofinnovation in organizational it according to organizational, environmental, innovation and human factors in zanjan industrial towns. J. Fundam. Appl. Sci., 2016, 8(2S), 1481-1492. 